\title{
THE INTELLECTUAL DISABLED (MENTALLY IMPAIRED) IN THE INCLUSIVE TYPE OF EDUCATION: PROBLEMS AND IMPLICATIONS.
}

\author{
OBASEKI F.N. \\ School of Education, \\ College of Education, \\ Ekiadolor Benin \\ and
OSAGIE-OBAZEE G.E
School of Education, College of Education, Ekiadolor Benin

\begin{abstract}
The Intellectual disabled child is characterized by significantly sub average general intellectual functioning, with concurrent deficits in adaptive behaviour. Sub average intellectual ability that is present from birth or infancy_is manifested by abnormal development, learning difficulties, and problem in social adjustment, very few of intellectual disabled are institutionalized; most of them now live independently with few of their families or in group homes. The emphasis on education is seen in the late 20th century. The schools are responsible for providing appropriate education and many teachers and parents' feels that inclusion of intellectual disabled in their educational system will make the intellectual disabled feel as a part of the society and will make others understand them better in their special needs and capabilities. This study therefore highlighted definitions, identifications and characteristics of the impaired child, and mentally impaired in inclusive education and lastly problems and prospects of mentally impaired. Recommendations were made.
\end{abstract}

Key words: Basic Education, mentally impaired, inclusive Education, Nigeria.

\section{Introduction}

The term intellectual disability carries different meanings. It represents medical as well as psychological grouping of children. Some psychologists define the term mental impairment as a diagnostic term designed to capture and standardize a group of disconnected categories of mental functioning such as "moron", "imbecile", and "idiot" derived 
from early intelligent quotient (IQ) test, which acquired pejorative connotations in popular discourse over time. Later these terms were softened and classifications redefined some what to mild (IQ of $55-70$ ) moderate (40-54) severe (25-39) profound (0-24) impaired (American Association on mental retardation, Definition, Classification, 1992).

The term "mental impairment" has acquired some pejorative and shameful connotations over the last few decades. Due to the use of impairment as an insult, these may in turn have contributed to its replacement with expressions such as "mentally challenged" or "intellectual disability".

In England and Wales between 1983 and 2008, the Mental Health Act 1983 defined "mental impairment" as a state of arrested or incomplete development of mind which includes significant/severe impairment of intelligence and social functioning associated with abnormal aggressiveness or seriously irresponsible conduct on the part of the person concern.

Grossman 1977 also refer mental impairment as significantly subaverage general intellectual functioning existing concurrently with deficit in adaptive behaviour manifested during the developmental period.

In the field of special education, educable (or "educable mentally impaired") refers to mentally impaired students with IQs of approximately $50-75$ as who can progress academically to a late elementary level.

Trainable (or "trainable mentally impaired") refers to students whose IQs falls below 50 but who are still capable of learning personal hygiene and other living skills in a sheltered setting, such as a group home.

The phrase intellectual disability is increasingly being used as a synonym for people with significantly below average cognitive ability. These terms are sometimes used as a means of separating general intellectual limitations from specific limited deficits as well as indicating that it is emotional or psychological disability.

Intellectual disability may also be used to describe the outcome of traumatic brain injury or lead poisoning and dementing conditions. It is not specific to congenital disorder such as Down syndrome.

Therefore children with intellectual disability will have limitation thinking skills including the ability to reason (working things out) and remembering. They will have difficulties with attention and organizing information. Children with intellectual disability have trouble seeing how things or how event relate to each other. For example they may find it difficult to understand that forks, knives, and spoons all belong to a 
bigger category called cutlery. In order to learn effectively children with intellectual disability will need certain type of structure and support.

\section{Identification/Characteristics of Impaired Children}

Sub average intellectual that is present from birth or infancy is manifested by abnormal development, learning difficulties, and problems in social adjustment in the school system today. In the school system, an intellectual disabled child can easily be identified by the teacher on the basis of daily observation in the class and outside class.

Group test of intelligence may be used to screen impaired children at the preliminary stage on the basis of their IQ, individual test of intelligence may be used with the group test to reach definite conclusion. Achievement test in various subjects should be used to know the level of achievement of impaired children. Personality inventory and case history may also be used.

On the basis of research studies conducted in recent years certain general characteristics of impaired children have been generalized. Impaired children when compared with normal children have been found inferior in physical development. They have poor muscular coordination, slower reaction time, more physical defects of eyes, nose and serious speech defects.

The chief deficiency in impaired children is in the area of intelligence. They have lesser capacity of abstract thinking and to correlate various experiences. They lack in reasoning ability. They lack the ability to think in abstract way.

The social development of impaired children lags behind the normal children of their age. This is because of two reasons. First the perception of social situation is a matter of understanding, and in the second place a child's impairedness has been apparent in the family and in the neighbourhood long before he enters the school. His classmate rejects him. Parents are ashamed of such children. They make sharp remarks and make unfavourable comparisons. These children develop undesirable social traits. They make good adjustment in non-academic pursuits as a compensatory defence mechanism. They are good followers and highly appreciate what is done for them. They stick to their friends and develop successful adjustments. The incidence of cheating is higher in them. 


\section{Mentally Impaired Child and Inclusive Education}

Implicit in the world submit for children declaration on education as in the convention on the rights of the child is the right of the child to basic education (FGN/UNICEF, 1993). The United Nation and the African union as well as other international organizations have stressed the need for all countries to make the optimum development of their citizens a priority in their welfare

Nigeria like other country of the world has introduced basic education programmes at different times. In order provide equal educational opportunities to all her citizens in respective of their status.

It is pertinent to note however that the objective of such a mass literacy campaign cannot fully achieve the desired objectives if there is no adequate plan to take care of the interest of all the citizens including the impaired children of school age.

Most importantly is the general attitude of people to mentally impaired children, although there has been an increasing awareness on the need to give these categories of children proper education yet many people and organizations do not know much about them.

While it is true that special schools sometimes receive some assistance from individuals and organizations. Such assistance are not regular. Majority of donations to this special of the year are forgotten and the impaired children are left to their fate.

Nevertheless, it would seem as if Government has deliberately concentrate more on the education of the normal citizens (both young and old) in the country at the expense of the unpaired children by and large, to neglect the impaired in their education is to make a mockery of Nigerians philosophy of education which is based on the integration of the individual into a sound effective citizen and equal educational opportunities for all citizens of the nation at the primary, secondary, and tertiary levels both inside and outside the formal school system (FRN, 2004). In other to rectify this obvious anomaly, it is necessary to identify the major areas of national focus in the education of the impaired children in the $21^{\text {st }}$ century and ensure the inclusion of the impaired children in the educational system therefore promoting equity among all children of school age.

Problems of the Mentally Impaired (Intellectual Disabled Child) in the Inclusive System.

According to the report by Situation and Policy Analysis of Basic Education (S.A.P.A) in Nigeria national report Lagos on special schools of the survey about $50 \%$ are owned by the state government $20.9 \%$ by 
religious organizations, $7.5 \%$ by local government, $32.0 \%$ by non governmental organizations, $3.0 \%$ by federal government and $1.5 \%$ by community

The relatively few number of special schools in the country means that many impaired children will have no access to formal education. The end result of course will be that impaired children will have adjustment problems in regular classes, the assignment given to him either are too difficult or he has fallen too far behind his grade level to understand and perform the task required of him in a regular classes

The impaired child lacks motivation to learn, either because his background has been too deprived, his home induced emotional problems are too severe or his learning attempts have received no suitable encouragement or consistent by the teacher. He has become failure oriented because of repeated defeats and thus no longer believes in himself capable of learning. He fears failure and lacks ability and confidence to initiate new activities.

The material, he is assigned, has not been made meaningful to him, so he sees little purpose in learning it. He is flooded with anxiety produced by the defence he has created against self-devaluation.

He is bitter and hostile towards school and society because of the humiliation he has suffered. The school environment provides him no motivation to work.

However it is been feared that even under the best condition no teacher has time to furnish the numerous illustration to permit the endless repetitions necessary for adequate learning of the impaired children. Thus, it is concluded that sufficient individual attention cannot be provided to the impaired children in regular class arrangement. So educationist advocate separating the impaired children in special classes were there can be gradually trained to cope with normal situation. There are some objections against these arrangements. These objections are, parents do not like the isolation of their children from normal children and that such school are very expensive to run and the equipments are costly. No motivations and competitions are provided in such schools.

\section{Prospects}

To ensure that the education of the impaired are provided in all parts of the country, the federal government is to set up the commission that should be responsible for the funding, administration and the supervision of the education of the impaired at all levels. This will ensure that education of the impaired are provided in all parts of the country, both in 
rural and urban centres. This will ensure the inclusion of the impaired children in the educational system thereby promoting equity among all children of school age.

The government should provide conducive environment for learning in the school is basic to the success of any educational program. It is not enough to provide school. The school environment must be attractive and suitable for effective teaching and learning to take place. Generally, most of the impaired children suffer from emotional problems. No doubt these children need new experiences and a richer environment to stimulate them intellectually, but they need stability and a protected environment for their emotional difficulties. One of the most important aspects of remedial treatment is the deliberate attempt to extend child's environment. It should be extended by enrichment of experiences in the class and outside the class. Such educational measures will generally facilitate the children ability to come to grip with the word in a more effective way.

The federal government should focus on both literacy and vocation training for impaired children. Since education of various categories of impaired children will be involved, it will not be enough to just provide literacy and numerous skills in the school, as we are all aware many of the children will never go beyond primary schools for various children therefore whatever education they are given should include the acquisition of certain / vocational skills with which they could provide for their immediate needs in future rather than becoming a burden on the society.

\section{Recommendations}

For impaired children to reach their full potentials and make meaningful contribution to the development of the country they require a lot of understanding, patients, and encouragement. Teachers should plan such activities for impaired children, which give motivation to the impaired child. It is sometimes argued that such children should be taught using visual and concrete material and abstraction should be kept to the minimum. Thus use of visual and concrete material in the teaching of impaired should be viewed as a means and not an end. These children understand and embrace the goal, they work with material, they can manage, they learn things in relation, they repeat many times what they have learned, and learn things in relation, they repeat many time what they have learned, and they work as a group in forwarding the project. In practical terms this means that impaired child will need more practice in problem solving activity. 
The learning of generalization, abstractions, and concept is difficult for impaired children. The impaired child needs more concrete illustrations, especially, those he himself can manipulate and help in locating the attributes in each experience.

The teacher should try to improve the social competence of impaired children. They should be helped to get well with others and to become successful members of the community in which they live.

The teacher must use the following recognized principle of learning:

He must be taught in simple steps that he can master at his own pace. Input over load can only result in selective retention and frustration.

He must receive immediate reinforcement for any success. This is necessary to insure repetition of his successful behaviour.

He must receive a variety of stimulation, since all children do not learn in the same fashion or by same means.

The material should be made meaningful to him to insure retention.

He should be provided with immediate knowledge of the result of his work. If not, he has no feedback to guide further activity.

He must be given the opportunity to practice his knowledge and skill through distributed repetition and a variety of appropriate tasks.

His primary instruction at every level must be initiated through careful training, and then painstakingly shaped by increasingly accurate corrections which are reinforced.

\section{References}

Akinbote, O. (1995) Primary Education for National Development: The Nigerian Experience. Dougirei J. Edu. 5:72-77

Awolowo, O. (1976). The Economics Well-Being of the Individual in Fawehinmi Gani (Ed), Awo on Free Education. Ibadan Sketch Publishing Co.

Federal Republic of Nigeria (2004) National Policy on Education. Lagos: NERDC Press.

FGN/UNICEF, (1993) situation and Policy Analysis of Basic Education in Nigeria: National Report. Lagos: Federal Ministry of Education.

FME/UNICEF, (1993) Basic Education Statistics and Trend in Nigeria, Lagos.

Hanson, J. W. (1964), The National Educational Purpose in Ikejiani, O. (Ed) Nigeria Education, Ikeja. Longman Nigerian Ltd.

Shenberger, P. (2005) Exceptional Children http://ohioline.osu.edu/hygfact $/ 5000 / 5256 \mathrm{html}$. 